\title{
THE EFFICIENCY OF THE COGENERATION UNIT IMPLEMENTED IN THE CHS SYSTEMS IN TERMS OF HEAT GENERATION
}

\author{
Miroslav Rimár \\ Technical University of Košice, Faculty of manufacturing technologies with a seat in Prešov, Department of process \\ engineering, Sturova 31.080 01, Tel.: 055/6026341 email: miroslav.rimar@tuke.sk

\section{Marcel Fedák} \\ Technical University of Košice, Faculty of manufacturing technologies with a seat in Prešov, Department of process \\ engineering, Sturova 31.080 01, Tel.: 055/6026330 email: marcel.fedak@ tuke.sk

\section{Milan Abraham} \\ Technical University of Košice, Faculty of manufacturing technologies with a seat in Prešov, Department of process \\ engineering, Sturova 31.080 01, Tel.: 055/6026335 email: milan.abraham@ tuke.sk

\section{Andrii Kulikov} \\ Technical University of Košice, Faculty of manufacturing technologies with a seat in Prešov, Department of process \\ engineering, Sturova 31.080 01, Tel.: 055/6026335 email: andrii.kulikov@ tuke.sk

\section{Jakub Váhovský} \\ Technical University of Košice, Faculty of manufacturing technologies with a seat in Prešov, Department of process \\ engineering, Sturova 31.080 01, Tel.: 055/6026335 email: jakub.vahovsky@ tuke.sk
}

Keywords: CHS, cogeneration, heat, electricity, efficiency

Abstract: Presented paper is dedicated on issue of the operation of a cogeneration unit integrated in the central heating system. An evaluation of the efficiency of the cogeneration unit operation is performed during heat water preparation and later the heating season. Indicators are evaluated as the correlation between the primary fuel and the electrical and thermal energy consumption. The main idea is following combined generation of electricity and heat with look at efficiency of the cogeneration unit in the central heat supply system in terms of heat generation.

\section{Introduction}

Integration of renewable energy and cogeneration system for heat generation on the basis of act no. 309/2009 [1] becomes an important part of energy generation. This integration into the national heat and power generate network may be either as separate sources or as a part of central systems for the power and thermal energy generation. These changes are conditions for the implementation of directive of the European parliament and the council 2004/8/ES, which is and indispensable part of the development of the internal market of energy as well as measures of safeguard for electric energy supply. Within the development of energy systems primary support of cogeneration is based on the demand of usable heat. It is necessary to consider with the directive of the European parliament and of the Council of EU 2012/27/EU on energy efficiency, when implementing energy sources. Based on the development as mentioned in the [2] in the next years the greatest potential will be in the highly efficient heat and power generation sector especially in the segment of existing small and medium heat sources (heat plant, central district heating boilers) in which natural gas is incinerated by installation of combined heat and power technology with combustion engines.
The paper is devoted to the technology issue of integration the principle of cogeneration unit in multivalent systems of CHS (central heat supply) and consequently to increase efficiency of the source. The main purpose is to describe efficiency of the cogeneration unit operation integrated in the central heat supply system in particular periods of summer and winter season. According to the point that the natural gas is still assumed as the dominant fuel for heat production [3], cogeneration is a suitable source for high efficiency combined generation. The cogeneration system is usually designed and optimised according to economic and energy requirement with regard to environmental criteria and is usually autonomously controlled by microprocessors and current demand for energy.

\section{Cogeneration in multivalent systems of central heat supply}

The main idea of installing cogeneration unit in the central heat supply is to reduce energy costs, pollution and increase efficiency through the integration of renewable energy sources such as biogas and combined energy production. The production of heat and its delivery as final product is a sector whose operation is important not only from the aspects of industrial generation processes, but also from a social point of view. From the aspect of the 


\section{THE EFFICIENCY OF THE COGENERATION UNIT IMPLEMENTED IN THE CHS SYSTEMS IN TERMS OF HEAT GENERATION}

Miroslav Rimár; Marcel Fedák; Milan Abraham; Andrii Kulikov; Jakub Váhovský

generation of thermal energy for the final customer the advantage of the central heat supply compared to other forms are relatively low prices for heat, in connection with the increase of the usage of cogeneration. Negative influence on the size of the market with heat was also the disconnection of customers from central heat supply, which to the future is also not considered to such a big extent. Currently has been adopted legislative framework which establishes conditions for termination of sampling and practically making it impossible for customers to disconnect from heat sources using renewable energy sources [2] as stated in [3] the electric energy produced in combined production of heat and energy is exempt from taxes, if it is directly delivered to the final consumer of electric energy. It is possible to facilitate access to the electricity grid produced by high efficiency cogeneration on the basis of 2004/8/ES, in particular in the case of lowmpower cogeneration unit and micro cogeneration units. Development of the share of electricity production by high efficiency combined production to total electricity in Slovakia is shown in the figure 1.

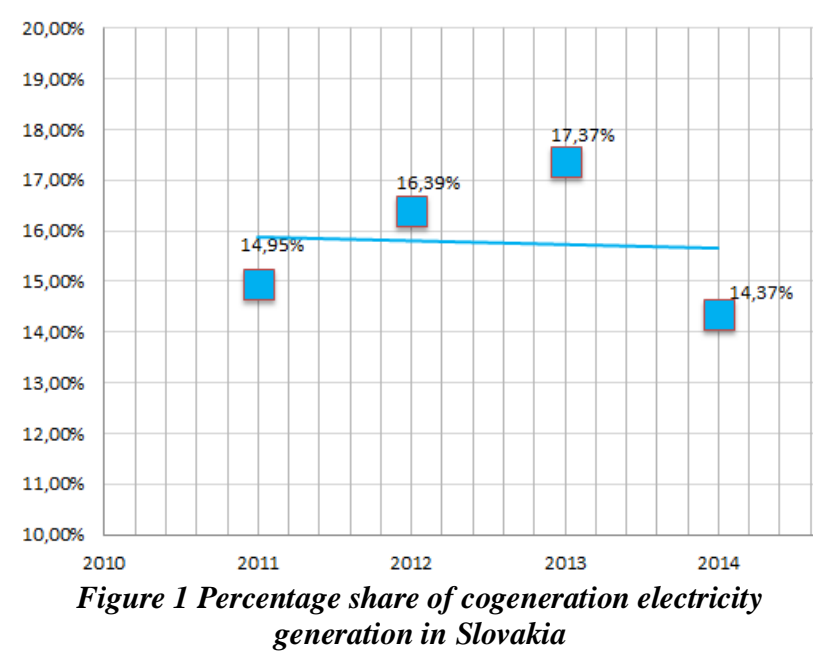

The amount of primary energy savings and the amount of $\mathrm{CO}^{2}$ savings achieved over the period 2011-2014 by high efficiency cogeneration are shown in the following graph.

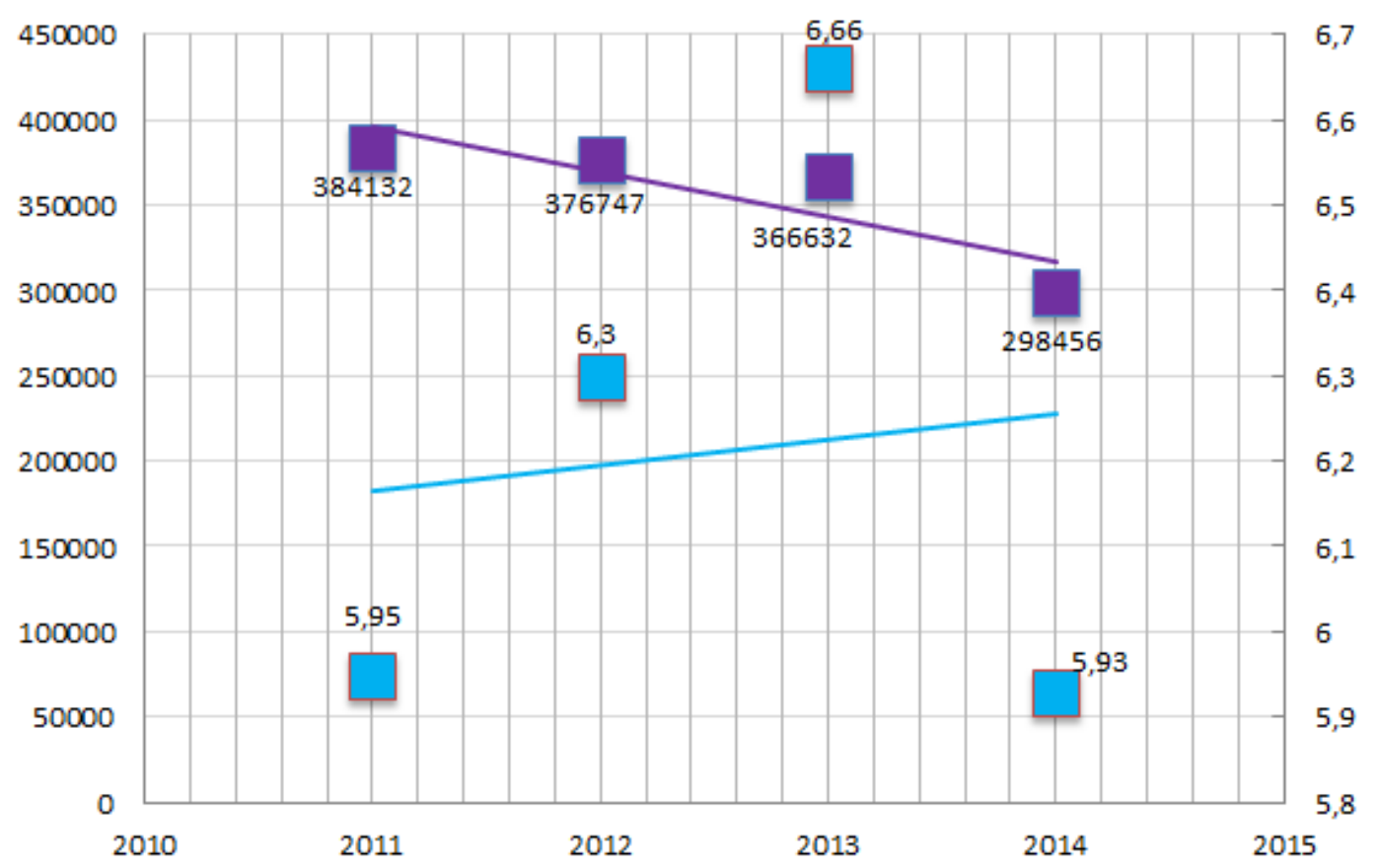

Figure 2 Amount of primary energy savings and the amount of CO2 savings

Heat supply nowadays requires part of the primary energy sources and the simplest way is to burn fuel and process generated heat then sends it to the customer. The efficiency of similar processes is high (80 to 100\%), but fuel exergy is lost. Combined electric energy and heat production which represents cogeneration is energy more efficient way of obtaining heat. Figure 3 shows existing and assumed by the 2025 electric and thermal power of CHP (combined heat and power) plants according to the type of technology of combined energy generation [5]. The expected increase in electricity production in systems CHP using the combustion engines in 2025 predicts about $720 \%$ growth over 2011.

As shown in the following there is a direct correlation between generated electrical energy and produced heat. There is certain difference, due to the type of operation and the period. 
THE EFFICIENCY OF THE COGENERATION UNIT IMPLEMENTED IN THE CHS SYSTEMS IN TERMS OF HEAT GENERATION

Miroslav Rimár; Marcel Fedák; Milan Abraham; Andrii Kulikov; Jakub Váhovský

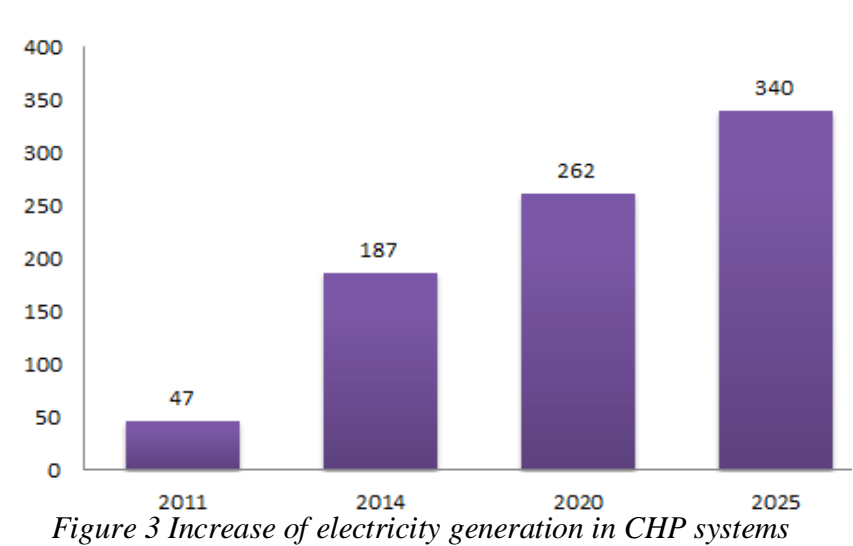

\subsection{Combined energy production}

Combined heat and power generation is one of the most efficient technologies to reduce primary fuel
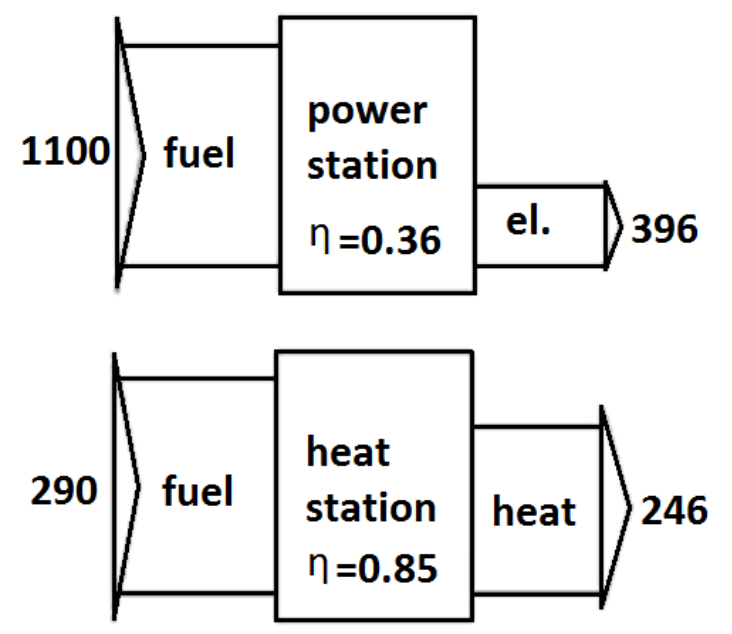

Figure 4 Conventional energy generation compared to combined energy

The main part of cogeneration unit is an engine that normally supplies an asynchronous generator. The engine itself consists of conventional carburettor for combustion mixed air and natural gas or various biogases. Each part of the cogeneration unit is placed in container with the noise and vibration reduction.

\section{The efficiency of the cogeneration unit in the CHS}

In order to carry out an evaluation of operational characteristics and efficiency is the selected cogeneration unit (Fig. 5) integrated within the CHS system. The cogeneration unit is operated in the primary mode of heat generation and it is production of electricity depends on the demand for actual heat production. The cogeneration unit in the given mode of operation provides heating and prepares hot water for approximately 1600 apartments, elementary schools and shopping centres located in its surroundings. The cogeneration unit itself consist of a gas fuel consumed. consumption and emission. The efficiency of combined energy production is described in fig. 4. The electrical efficiency of cogeneration unit is around 40 to $50 \%$. The performance and operating time of cogeneration unit is limited by the operating hours during the summer season. In the winter season the cogeneration unit is operated 24 hours a day, during the summer season it is in operation for 18 to 19 hours a day. Increasing the efficiency of cogeneration unit from a physical point of view is not possible with current technology in the case of using the conventional fuels. However, there are several ways to increase efficiency one of them is integrating to it external RES (renewable energy sources) to make them multivalent systems of central heat supply.

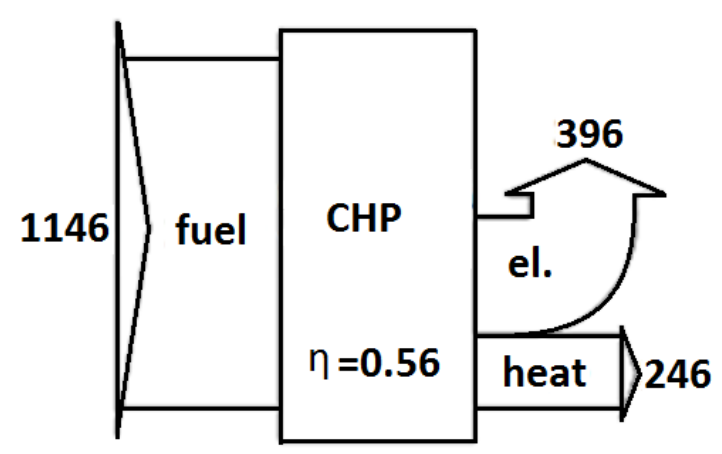

combustion engine MWM/TCG 2016 V12C with a generator that provides $600 \mathrm{~kW}$ of rated electric power and $650 \mathrm{~kW}$ of rated thermal output. The electrical efficiency of this cogeneration unit is around $42,19 \%$. The operating time of the cogeneration unit is limited by the operating hours (18 to 19 operating hours) during the summer. The actual operation of the device in this case is experimentally conditioned by the production of thermal energy. In the winter the cogeneration unit is operated 24 hours a day. The equivalent calorific value is added to the amount of 


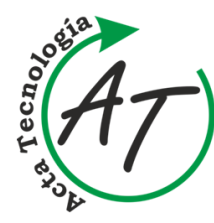

THE EFFICIENCY OF THE COGENERATION UNIT IMPLEMENTED IN THE CHS SYSTEMS IN TERMS OF HEAT GENERATION

Miroslav Rimár; Marcel Fedák; Milan Abraham; Andrii Kulikov; Jakub Váhovský

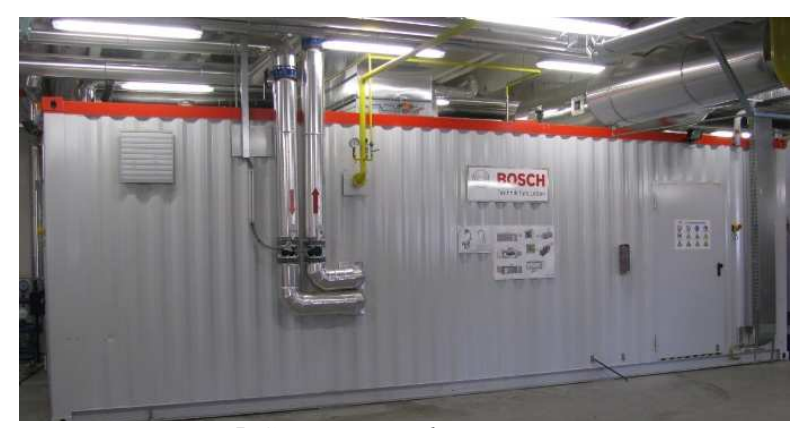

Figure 5 Container with cogeneration unit

\subsection{Efficiency of energy production in individual seasons}

The measurements were realised in winter and summer operating mode in 2016. As monitored parameters was quantity of consumed fuel for each period of time and the amount of produced heat and electric energy. After that conversions were made were determined the operational efficiency for heat and electricity production. Figure 6 shows the dependence of the energy produced on the fuel consumed.

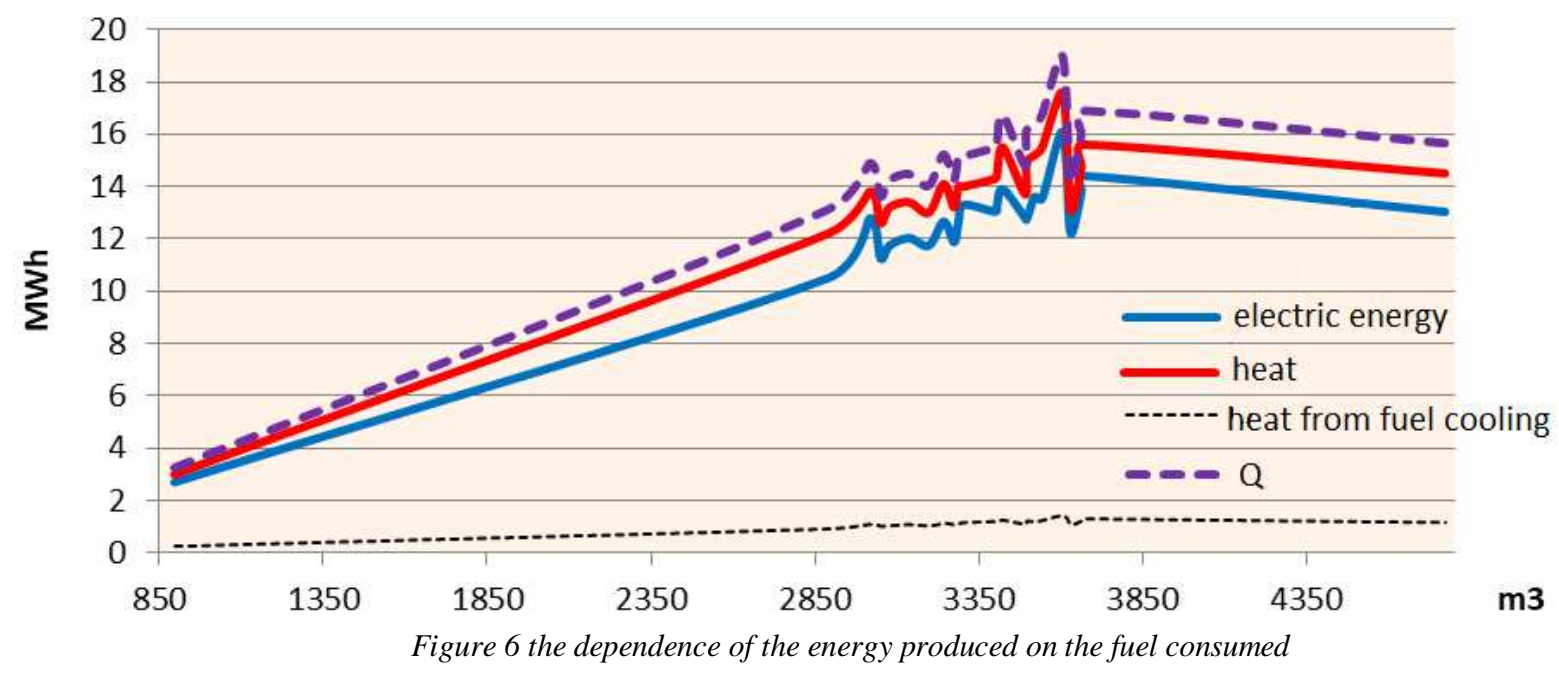

On the basis of the modified equation for the monthly calculation of primary energy savings and the determination of efficiency, the thermal efficiency of cogeneration is the monthly generation of usable heat divided by the amount of input fuel used to produce the sum of usable heat and electricity through cogeneration; the electrical efficiency of cogeneration is determined as input fuel used to produce the sum of the usable heat and electricity. The summary amount of the electrical and thermal energy produced by the cogeneration unit and divided by the theoretical value of the energy contained in the given amount of fuel, the percentage efficiency of the cogeneration unit is shown in figure 7.

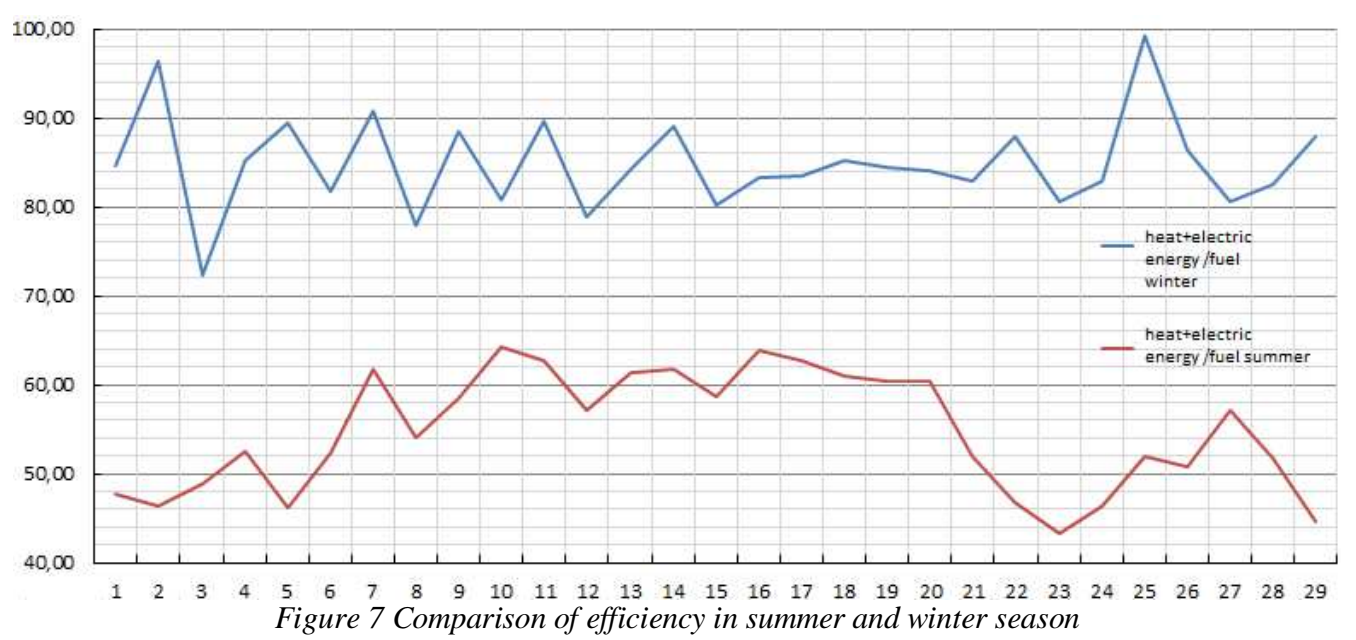

The following figure describes the same but comparing with the previous one, it displays thermal and 


\section{THE EFFICIENCY OF THE COGENERATION UNIT IMPLEMENTED IN THE CHS SYSTEMS IN TERMS OF HEAT GENERATION \\ Miroslav Rimár; Marcel Fedák; Milan Abraham; Andrii Kulikov; Jakub Váhovský}

electrical energies separately. The priority of the cogeneration in this case is the production of thermal energy.

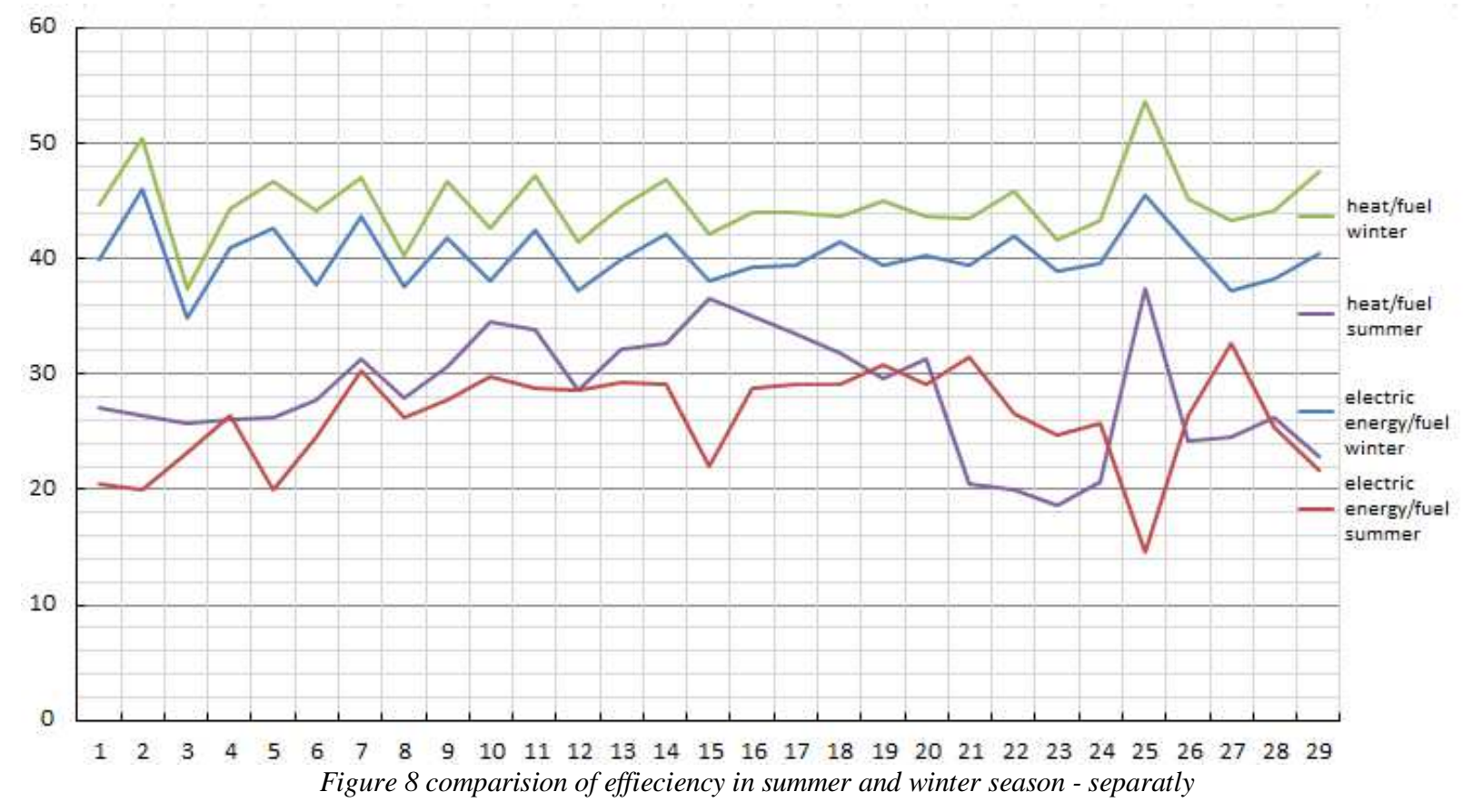

\section{Conclusions}

The assumed increase in electricity production in CHP systems using combustion engines in 2025 represents about $720 \%$ growth comparing with 2011, which represents a significant share in the ratio of heat produced by CHP equipment. As shown, there is a direct correlation between the generated electrical energy and the heat. However, there is a certain difference due to the type of operation and the period of operation. According to the point that the natural gas is still assumed as the dominant fuel for heat production, cogeneration is a suitable source for high efficiency combined generation.

\section{Acknowledgement}

This paper is supported by the VUKONZE - Research Centrum for Combined and Renewable Resources of Energy ITMS code: 26220220064

\section{References}

[1] Act No. 309/2009 Coll. on promotion of renewable energy sources and high efficiency combined generation, and on amendments and supplements of certain Acts in the version of latter provisions, 2009.

[2] Directive 2004/8/EC of the European Parliament and of the Council of 11 February 2004 on the promotion of cogeneration based on a useful heat demand in the internal energy market and amending Directive 92/42/EEC, 2004.
[3] Ministry of Economy of the Slovak Republic, Slovak innovation and energy agency, Economic and technical assessment of CHS application in SR and comprehensive assessment of national potential for CHS implementation comprehensive assessment of national potential for the application of highly efficient cogeneration, 2015.

[4] STRUŽ, M.: Utilization of CHP in Slovakia and its further outlook, 2014.

[5] BOSZORMENYI, L., GAVLÍK, M., BOSZORMENYI, L.: Sustainable supply of energy for buildings from renewable energy sources, Košice, 2013.

[6] KRBEK, J., OCHRANA, L., POLESNÝ, B.: Heat supply and cogeneration, Brno, 1999.

[7] RIMÁR, M., SKOK, P.: Thermodynamics, Prešov University, FVT, p. 86, 2013.

\section{Review process}

Single-blind peer reviewed process by two reviewers. 